\title{
Snake bite-induced myoclonus, myokymia and myospasm with leukoencephalopathy: a video presentation
}

\author{
Kanterpersad Ramcharan ${ }^{1,2}$ Kamille Abdool, ${ }^{1}$ Navindra Persad, ${ }^{1}$ Adrian Alexander ${ }^{1}$
}

${ }^{1}$ Department of Medicine, San Fernando Teaching Hospital, San Fernando, Trinidad and Tobago

${ }^{2}$ Department of Medicine, Surgi-Med Clinic, San Fernando, Trinidad and Tobago

\section{Correspondence to} Dr Kanterpersad Ramcharan, kramcharan79@yahoo.com

Accepted 5 April 2016

\section{DESCRIPTION}

A 41-year-old man, a previously healthy herpetologist, was admitted $3 \mathrm{~h}$ after being bitten on the left hand by a pit viper snake (species-Bothrops atrox), the natural habitat of which is the Central and South American, and West Indian rainforests. The patient developed vomiting, abdominal pains, limb myalgia, paraesthesia and diffuse muscle twitching. $\mathrm{He}$

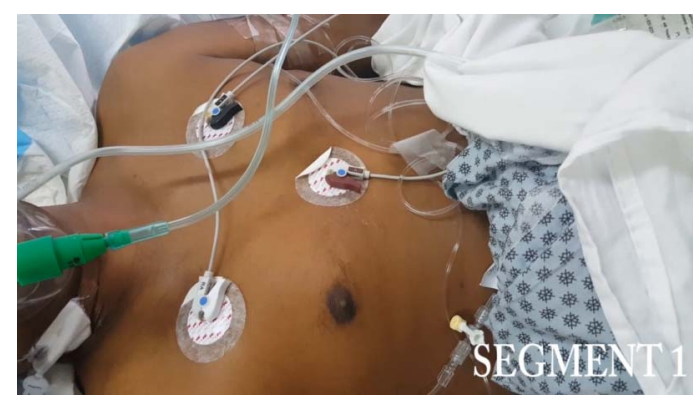

Video 1 Segment 1 and 2 showing myoclonus of the pectoralis muscles bilaterally, and myokymia and myospasm in the right thigh muscles. became confused, then apnoeic and received mechanical ventilation for 3 days. Myoclonus of pectoralis muscles bilaterally and right quadriceps was noted for 2 days. Myokymia and myospasms were observed in the thigh muscles (video 1 , segments 1 and 2). Blood investigations were normal. Two phials of polyvalent snake antivenom were administrated intravenously as recommended by the National Poison Centre of Trinidad and Tobago. The blood pressure was never elevated.

Electromyogram showed increased neuronal excitability with mild myopathic features. EEG showed cortical irritability in the left centroparietal and temporal area (figure 1).

MRI of the brain performed on day 6 showed multiple subcortical white matter hyperintensities in the frontoparietal and occipital lobes, with normal basal ganglia on axial T2-weighted views (figure 2A-C). At discharge on day 14, there was full recovery. A repeat MRI was not obtained.

Posterior reversible encephalopathy syndrome and snake bite leukoencephalopathy causing cortical rim and basal ganglia hyperintensities with Parkinsonism due to viper envenomation have both been described but without EEG findings. ${ }^{1}{ }^{2}$
To cite: Ramcharan $\mathrm{K}$, Abdool K, Persad N, et al. BMJ Case Rep Published online: [please include Day Month Year] doi:10.1136/ bcr-2016-214963

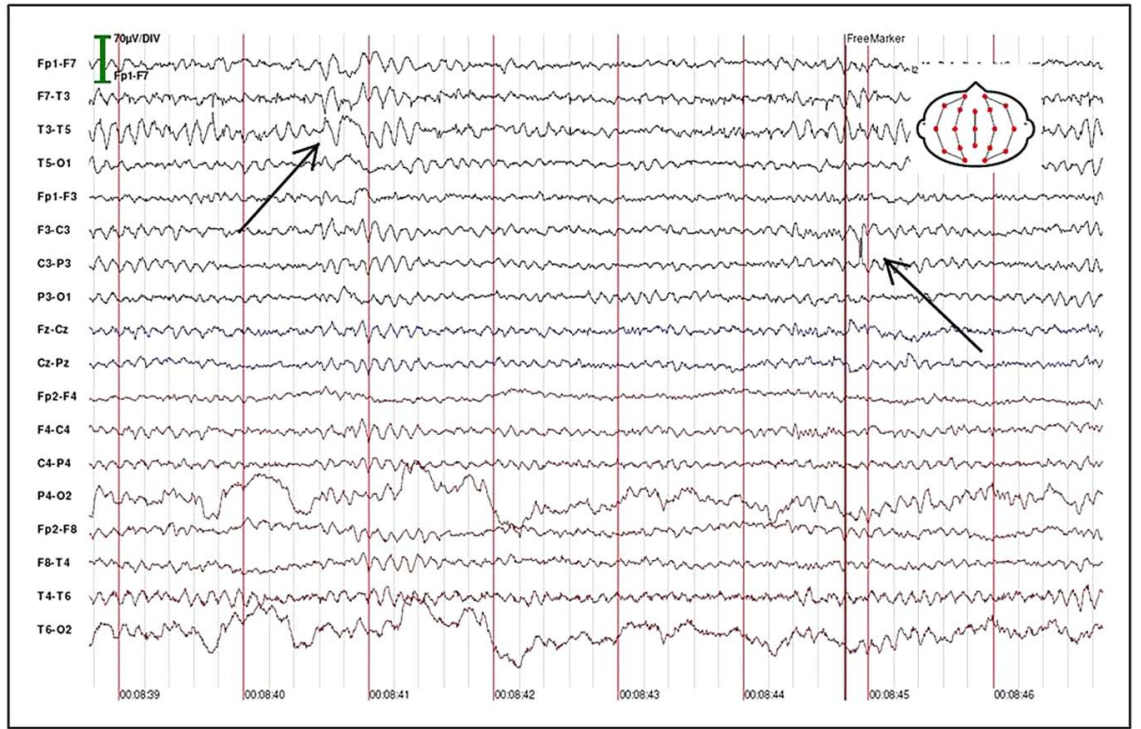

Figure 1 EEG showing isolated spike in C3 derivation, and sharp and slow wave complex in T3 derivation, consistent with cortical irritability in centroparietal and temporal areas of the left hemisphere. 
Figure 2 (A) Axial T2-weighted brain MRI showing minimal diffuse subcortical hyperintensity in the left occipital area (see arrow). (B) Axial T2-weighted brain MRI showing minimal diffuse subcortical hyperintensities in the right occipital area, bilateral centroparietal and right frontal area (see arrows). (C) Axial T2-weighted brain MRI showing normal basal ganglia.
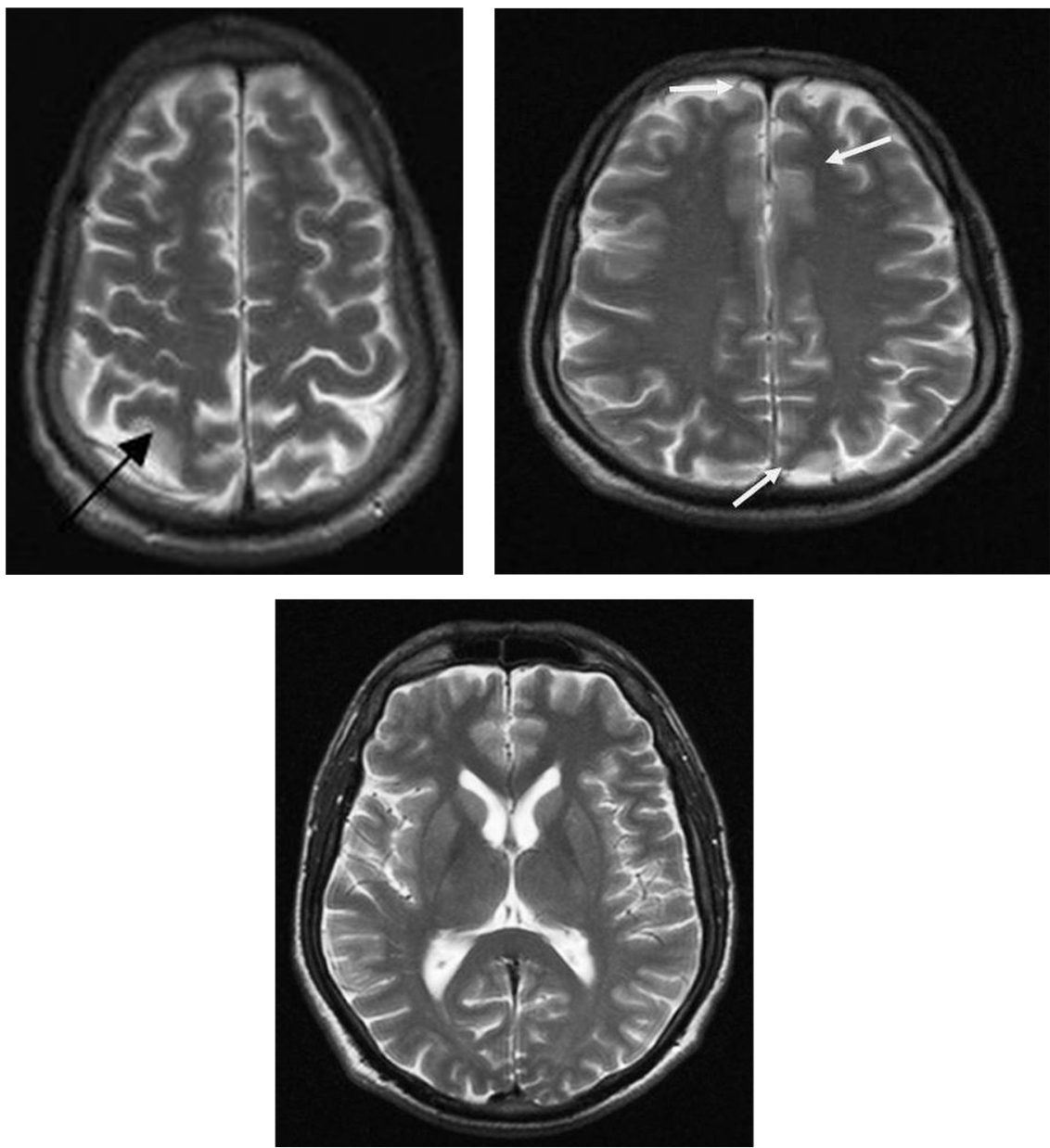

Myokymia has been described in envenomation by the North American viper (rattlesnake), but descriptions with myoclonus and myospasms were not found. ${ }^{3}$

The pathogenesis remains unclear.

\section{Learning points}

- Snake envenomation has a high mortality rate globally, and is considered a neglected global health issue causing considerable mortality and morbidity.

- Myokymia is well recognised following snake envenomation and is considered a warning sign for possible artificial ventilation.

- Movement disorders and other neurological manifestations in snake envenomation are interesting phenomena needing further elucidation.
Acknowledgements The authors would like to thank Dr Isvan Alvarez Herrera who performed the neurophysiological studies. Dr Antonio Jose Reyes reviewed the manuscript. Dr Shane Karim edited the video. Ms Sharon Sealy prepared the medical images.

Contributors AA and NP drafted the manuscript. KA and KR contributed to the final manuscript. All the authors managed the patient.

Competing interests None declared.

Patient consent Obtained.

Provenance and peer review Not commissioned; externally peer reviewed.

\section{REFERENCES}

1 Chaudhary SC, Sawlani KK, Malhotra HS, et al. Snake bite-induced leucoencephalopathy. BMJ Case Rep 2013 Jan 18; doi:10.1136/bcr-2012-007515

2 Varalaxmi B, Ram R, Sandeep P, et al. Posterior reversible encephalopathy syndrome in a patient of Snake bite. J Postgrad Med 2014;60:89-90.

3 Lewis RL, Gutmann L. Snake venoms and the neuromuscular junction. Semin Neurol 2004;24:175-9. 
Copyright 2016 BMJ Publishing Group. All rights reserved. For permission to reuse any of this content visit http://group.bmj.com/group/rights-licensing/permissions.

BMJ Case Report Fellows may re-use this article for personal use and teaching without any further permission.

Become a Fellow of BMJ Case Reports today and you can:

- Submit as many cases as you like

- Enjoy fast sympathetic peer review and rapid publication of accepted articles

- Access all the published articles

- Re-use any of the published material for personal use and teaching without further permission

For information on Institutional Fellowships contact consortiasales@bmjgroup.com

Visit casereports.bmj.com for more articles like this and to become a Fellow 